\title{
Simon Falch
}

\section{Maria - und Josef? Marianische Liturgie als Präzedenzfall für die Verehrung des hl. Josef}

Der Kult des Josef von Nazareth ist im Stellenwert nicht mit der hyperdulischen Verehrung der Gottesmutter zu vergleichen und doch auf das Engste mit der Entwicklung marianischer und eucharistischer Frömmigkeit verflochten. ${ }^{1}$ Denn es lässt sich wohl kaum „vom Geheimnis der Inkarnation“ bzw. „von der Erlösung reden“, ohne an Maria, aber auch an den Vater Jesu „vor dem Gesetz“ zu erinnern: ${ }^{2}$ Maria mater est Jesu [...]. Nutritius est Ioseph huius Iesu: est et custos, ut bonum et fructuosum sanctitatis propositum. ${ }^{3}$ Josef partizipiert somit immer an der Verehrung Jesu und Mariä, ohne im gleichen Umfang Person eigenständiger kultischer Verehrung zu sein - dabei ,beginnt [das Neue Testament] mit der Gestalt Josefs“,, ${ }^{4}$ und über dessen Abstammung ist der Messias, die Prophezeiung erfüllend, von davidischem Geschlecht. ${ }^{5}$ Doch neben der Bedeutung Josefs als Adoptivvater ${ }^{6}$ und Ernährer Christi im Heilsplan bieten auch seine Tugenden Anlass, seiner zu gedenken. Schließlich ist er der Garant für die Jungfräulichkeit der Gottesmutter, ${ }^{7}$ denn, so sei es nach Ambrosius in der Hl. Schrift festgestellt worden, ut et desponsata esset, et virgo: virgo, ut expers virilis consortii videretur:

1 Bei Thomas von Aquin fänden sich, so Berger (S. 137), „zwei eng zusammenhängende Grundgedanken [...]: Joseph als der jungfräuliche Ehemann der Gottesmutter und Joseph als der Vater Christi. Beide werden am intensivsten entfaltet in den Quaestionen über die Jungfräulichkeit und die Vermählung der Mutter Christi (IIIa, q. 28-29).“ Zum ,Wurzelfassen` der Josefsverehrung siehe Barth, S. 5-14.

2 Schumacher, S. 21. Wenig Forschungsinteresse am hl. Josef konstatiert Signori (S. 189).

3 Adamus Scotus: Sermones, ser. XXXVIII,9 (PL 198, 347B-C).

4 Wucherpfennig, S. 1; Lamarzelle, S. 532.

5 Josef stammt aus dem Haus David, also müsse dies auch für Maria gelten. Vgl. Johannes Chrysostomus: Kommentar zum Evangelium des hl. Matthäus, hom. II,1,IV: „Denn es war nicht nur nicht erlaubt, aus einem anderen Stamme jemand zu heiraten, sondern auch nicht einmal aus einer anderen Familie, d. h. Verwandtschaft.“

6 Berger, S. 143: „So könne man auch bezüglich der Vaterschaft des hl. Joseph von der proles als einem echten bonum matrimonii sprechen. Freilich ist dies so ungewöhnlich, dass die Thomisten von einer paternitas omnino sui generis, quae superat paternitatem adoptivam communem, et paternitatem nutritii sprechen.“

7 Vgl. Gerson: Epistola (Du Pin IV, Sp. 735C-D): Sentit hoc Hieronymus ,Epistola contra Helvidium'. Cujus dicti rationem ipse, ac posteriores multi talem tradunt: Joseph itaque priusquam jungeretur cum Virgine Maria corruptus, vel uxoratus non fuerat.

DOI 10.1515/9783110475371-010, (cc)BY-NC-ND (c) 2017 Simon Falch.

This work is licensed under the Creative Commons Attribution-NonCommercial-NoDerivs 3.0 License. 
desponsata, ne temeratae virginitatis adureretur infamia. ${ }^{8}$ Für die Absicherung des Dogmas der immerwährenden Jungfräulichkeit Mariens spielt Josef also eine zentrale Rolle:

Et ideo qui Incarnationis incorruptum susceperat probare mysterium, non putavit uberius prosequendum virginitatis Mariae testimonium; ne defensor magis Virginis, quam assertor mysterii crederetur. Certe quando iustum docuit Ioseph, satis declaravit quod sancti Spiritus templum, uterum mysterii, matrem Domini violare non potuit. ${ }^{9}$

Gerecht und keusch sei Josef, deswegen kann Petrus Damianus auf ihn verweisen, um seiner Forderung nach einer zölibatären Lebensweise des Klerus Nachdruck zu verleihen. ${ }^{10}$ Der Kanzler von Paris empfiehlt sogar auf dem Konzil von Konstanz der Kirche - als Braut Christi - den Bräutigam der unbefleckten Jungfrau als Schutzpatron, ${ }^{11}$ denn „,[d]urch die Ehe der jungfräulichen Gottesmutter mit Joseph werden nicht nur Ehe und Jungfräulichkeit zugleich geehrt, diese ist vielmehr ein Sinnbild für die ganze Kirche, die ,obwohl Jungfrau, dennoch mit einem Manne, Christus, vermählt ist (Augustinus)““..12 Im Franziskaneroffizium (1490) wird daher in der Vesper nachfolgende Antiphon gesungen:

\author{
Laetare, sponsa Christi, \\ alma mater ecclesia, \\ Sancti Ioseph, sponsae Mariae, \\ assunt sollemnia [...] \\ Senex beatus Ioseph et virgo III \\ Virginitatem suam \\ Ad honorem Dei \\ Servare semper promiserat, \\ Nisi Deus aliter iubeat, \\ Cui se totaliter commiserat. ${ }^{13}$
}

\footnotetext{
8 Ambrosius Mediolanensis: Expositio Evangelii secundum Lucam II,1,1 (PL 15, 1552D-1553A). Siehe auch Thomas de Aquino: Catena in Lc I,1,8.

9 Ambrosius Mediolanensis: Expositio Evangelii secundum Lucam II,1,6 (PL 15, 1555B).

10 Petrus Damiani: De caelibatu sacerdotum III (PL 145, 384D): Si igitur Redemptor noster tantopere dilexit floridi pudoris integritatem, ut non modo de virgineo utero nasceretur, sed etiam a nutricio virgine tractaretur, et hoc cum adhuc parvulus vagiret in cunis, a quibus nunc, obsecro, tractari vult corpus suum, cum iam immensus regnat in coelis? Zum ,Kampf gegen die Priesterehe‘ vgl. Zschoch, S. 30-31.

11 Vgl. Gerson: Sermo de nativitate (Du Pin III, Sp. 1358D). Siehe auch Seitz, S. 205.

12 Berger, S. 141-142.

13 AH 26, S. 181-184, Nr. 63; hier S. 181, Str. 1 und 3. Siehe auch Seitz, S. 356.
} 
Die Ehren des hl. Josef sind mannigfaltig, wie Petrus de Alliaco (Pierre d'Ailly) zu vermitteln weiß, zwölf an der Zahl, darunter freilich auch dessen Jungfräulichkeit. ${ }^{14}$ Ein ähnliches Lob stimmt Bernhard von Luxemburg auf bisher im Detail noch nicht nachvollzogener Kompilationsgrundlage an, ohne jedoch auf den Traktat des Petrus hinzuweisen, dessen zwölf Lobpreisungen hier lediglich als Nachtrag berücksichtigt wurden. ${ }^{15}$ Der Augustiner-Chorherr Balthasar Boehm aus Rebdorf ( ${ }^{\star}$ um 1462, †1530), dessen monumentales Euvre 2638 lateinische und 36 volkssprachliche Predigten umfasst, kann alle bis dahin bekannten Josefstraktate in Bezug auf die Informationsfülle überbieten. ${ }^{16}$ In seinem Traktat Von dem helligen vater Ioseph fügt er gegenüber Petrus de Alliaco, den er freilich häufig zitiert, fünf weitere Lobpreisungen hinzu: so find ich sibenczehen besundere grosse er vnd wirdikeit mit den wir erkennen sein grosse lob vnd preisung. ${ }^{17}$

\section{Balthasar Boehm}

$1^{\circ}$ hoch edel geporn in dise werlt (fol. $158^{\text {ra }}$ )

$2^{\circ}$ warer vnd noher frevndt [Mariae und Ihesu Cristi] noch dem pluet vnd fleisch (fol. $160^{\text {ra }}$ )

\section{Petrus de Alliaco}

$1^{\circ}$ ex nobilissima stirpe regia propagatur (fol. $1^{\text {r) }}$

$2^{\circ}$ nascitur [...] ex semine Dauid ex quo nascitur Maria [...] [e]x quo etiam [...] nascitur Christus filius dei [...] Christus, Maria et Ioseph vera consanguinitate iunguntur (fol. $1^{\mathrm{r}-\mathrm{v}}$ )

14 Petrus de Alliaco: Tractatus de duodeci honoribus sancti Joseph.

15 Bernhard von Luxemburg: Compilatio, fol. $9^{r-v}$. $\mathrm{Zu}$,Meister Bernart' siehe Weidenhiller, Sp. 743.

16 Eichstätt, UB, Cod. st 451, Florianus Federer (Lang?), Balthasar Boehm: Traktate und Sermones dt., darin der 9. Sermo: Von dem helligen vatter Joseph der do waß ein sponß der Junckfrawen Marie, fol. 157 $7^{\mathrm{ra}}-188^{\mathrm{va}}$, im Folgenden Joseph, Cod. st 451 (Nr. 9). Vgl. Keller, S. 263-268. In den Transkriptionen wurden Groß- und Kleinschreibung reguliert, Abkürzungen aufgelöst, Ligatur $s z$ handschriftengetreu als $\beta$ beibehalten und eine (modernisierende) Interpunktion eingeführt. Es findet sich kein Hinweis darauf, dass Boehm den Josefstraktat seines Zeitgenossen Bernhard von Luxemburg kannte, weder erwähnt er das Werk noch findet sich ein Eintrag im Rebdorfer Bibliothekskatalog, allein dessen Sermones de rosario beatissime virginis Marie sind verzeichnet. Siehe Ruf, S. 271, Z. 35.

17 Joseph, Cod. st 451 (Nr. 9), fol. $158^{\text {ra }}$. 
$3^{\circ}$ got der almechtig hot im geben seins suns Ihesu Cristi mütter, die kunigen der himel, zu einer elichen hauß frawen (fol. 161 ${ }^{\mathrm{va}}$ )

$4^{\circ}$ hoch gelobt auß dem ewangelio, wan es spricht Matheus [...] Ioseph, Marie man, der do was gerecht (fol. $163^{\text {rb-va }}$ )

$5^{\circ}$ got der vatter hot im enpfolen das kintpet, das do nit allein menschlich, sunder auch gotlich was (fol. 166 ${ }^{\mathrm{rb}}$ )

$6^{\circ}$ wurd geheissen ein hausvatter in dem aller helligsten hausgesindt (fol. 167 $7^{\text {ra }}$ )

$7^{0}$ wurdt scheinperlich figuri[r]t in dem helligen Ioseph, dem alt vatter, von dem gesc[h]riben stet Genesis 39 (fol. 169 ${ }^{\text {va }}$ )

$8^{\circ}$ man helt vnd schreibt in ein gantze reine $\mathrm{iu}[\mathrm{n}]$ ckfraw an leib vnd gemvde (fol. $171^{\mathrm{rb}}$ )

$9^{\circ}$ wurd clerlich gelert vnd vnterweist durch die helligen propheten (fol. 172 $2^{\mathrm{vb}}$ )

$10^{\circ}$ ist von got geert worden wie ein heimlicher rodts man in grossen gotlichen sachen (fol. $173^{\text {vb }}$ )

$11^{\circ}$ hot ser dugenthafftiglich gelebt mit der schon Maria (fol. $174^{\mathrm{vb}}$ ) $3^{\circ}$ sacratissime virgini matri dei matrimonialiter desponsatur (fol. $1^{v}$ )

$7^{\circ}$ ipse iustus euangelico testimonio comprobatur: Joseph inquit vir eius cum esset iustus (fol. $4^{\mathrm{r}}$ )

$4^{\circ}$ sanctus hic sponsus virginitatis titulo decoratur (fol. $2^{\text {r }}$ )

$10^{\circ}$ non solum veterum sed etiam nouorum prophetarum oraculis de hiis que de Xpo futura erant edocetur (fol. $7^{\mathrm{v}}$ )

$6^{\circ}$ ei tanquam celesti secretario secretum incarnationis Christi misterium a deo per angelum reuelatur (fol. $3^{\text {r }}$ ) 
$11^{\circ}$,9. Subdivisio: $:^{18}$ der demutig Ihesus hab enpoten der schon Maria, seiner mütter, vnd dem Ioseph, seinem zu gegeben vatter, groeß er mit worten, wercken vnd siten; hab in geheissen wi[r]diger her vatter vnd hab im gepogen sein knie (fol. $178^{\text {va }}$ )

$12^{\circ}$ wurd gelobt groslich in dem, wan er hot gedient dem sün gottes leiplich vnd geistlich (fol. 179 ${ }^{\text {ra }}$ )

$13^{\circ}$ wurd von got fast vnd groeß gelibt vnd von der junckfrawen Maria. Wan vnter in ist gewest ein grosse vnd besundere gotliche libe (fol. $179^{\mathrm{vb}}$ )

$14^{\circ}$ wurd ffast betrubt vnd geen $[\mathrm{g}] \mathrm{st}$ mit dem schon kind Ihesu vnd mit seiner liben mütter Maria in mangerley weiß (fol. 181 ${ }^{\text {rb }}$ )

$15^{\circ}$ das er offt ist visitirt vnd heimgesugt worden von den heligen engel auß dem gepot gottis (fol. 183 ${ }^{\text {rb }}$ )

$16^{\circ}$ got hot in offt einngelassen in sein heimliche redt vnd gotliche gro̊sse geschik vnd werck (fol. 184 ${ }^{\mathrm{vb}}$ )

$16^{\circ}$,3. Subdivisio: dem helligen Ioseph von dem engel (als Matheus sagt) [Klammer im Original] enpfolen, das er dem kind solt geben den nomen vnd heissen es Ihesus (fol. 185 $5^{\mathrm{ra}}$ )

$17^{\circ}$ ist von disem elend abgescieden mit sellikeit, sussikeit vnd gerechtikeit (fol. 187 ${ }^{\mathrm{rb}}$ ) $12^{\circ}$ non solum dei mater, non solum regina celorum et domina angelorum sed etiam dei filius rex et dominus omnium cui omne genii flectitur celestium, terrestrium et infernorum huic sancto Ioseph humiliter obediendo subicitur (fol. $9^{v}$ )

$5^{\circ}$ non solum ad virginis matris sed etiam ad filii eius obsequa singulariter deputatur (fol. $2^{\mathrm{v}}$ ) $11^{\circ}$ non solum prophetica sed etiam angelica allocutione sepe familiariter consolatur (fol. $9^{\text {r }}$ )

$9^{\circ}$ ipso presente multa et magna ac mira nostre fidei mysteria declarantur (fol. $7^{\mathrm{r}}$ )

$8^{\circ}$ nomen Ihesus [...] a sancto Ioseph hominibus solemniter publicatur (fol. $5^{\mathrm{v}}$ )

18 Untergliederungen $\mathrm{zu}$ den von Boehm genannten siebzehn Lobpreisungen, die selbst wiederum Detailfragen zum Gliederungspunkt traktieren sowie weitere Dilatationen zum Lob des hl. Josef vorbringen oder Exkurse bspw. zur Genealogie bieten. Die Auswahl der subdivisiones wurde hier auf die Parallelen zu Petrus' Traktat beschränkt, um exemplarisch eine Kompilationsgrundlage aufzuzeigen und gleichzeitig den Umfang der Abweichungen zu skizzieren. 
Dass ausgerechnet dieser Augustiner-Chorherr, der weder durch Amt noch durch Würden ausgezeichnet war, ${ }^{19}$ den nach derzeitigem Kenntnisstand umfangreichsten volkssprachlichen Josefstraktat (mit 64 Folioseiten) seiner Zeit kompilierte, überrascht in zweierlei Hinsicht: nicht nur, weil dieser ungewöhnlich lang geriet, sondern auch, weil Boehms Schwerpunkt auf dem Lob der Gottesmutter $^{20}$ und den hl. Jungfrauen ${ }^{21}$ liegt, denen Altäre in der Rebdorfer Stiftsund Gemeindekirche geweiht waren.22 Doch wird gerade so der von Kirchenvätern und -lehrern theologisch begründete Zusammenhang zwischen Marienund Josefsverehrung deutlich ${ }^{23}$ - dass das eine immer schon das andere einschließt. Daher wurde das Fest des Gemahls der Hl. Jungfrau gerade den Ge-

19 In Akrostichonform vermittelt Balthasar Boehm in Cod. st 344 dem Leser eine Selbstauskunft, vgl. Keller 1999, S. 66: Balthasar Behem in Stefft natus Erfordie promotus in Eistat ordinatus in Rebdorf pro[fessus] A[ugustinus]. Daraus geht keine spezielle Funktion im Rebdorfer Chorherrenstift hervor. Vgl. Fink-Lang, S. 81.

20 Boehm bietet 134 lateinische Marienpredigten (Signaturen der UB Eichstätt, Predigtzählung nach den originalen Angaben in den Predigtbänden, die Angabe des Anlasses ([S = Sermones de Sanctis] folgt der in der Predigtforschung üblichen Zählung nach Schneyer [CD-ROM]): S5 Cod. st 345 (Nr. 12-16) und Cod. st 423 (Nr. 125-129); zu S21 Cod. st 345 (Nr. 58-63) und Cod. st 423 (Nr. 189-201); zu S28 Cod. st 345 (Nr. 100-113) und Cod. st 423 (Nr. 244-256); zu de commemoratione virginis Marie ab aduentum domini vsque ad natiuitatem eius (vgl. Missale Eystetense, fol. CClV va) Cod. st 423 (Nr. 260-261); zu Mariae ad martyres Cod. st 424 (Nr. 40); zu S145 Cod. st 344 (Nr. 38-42) und Cod. st 424 (Nr. 97-108), in octava Cod. st 424 (Nr. 119); zu S59 in vigilia Cod. st 424 (Nr. 175-176), in festo Cod. st 344 (Nr. 73-85) und Cod. st 424 (Nr. 177-193), in octava Cod. st 424 (Nr. 200); zu S65 Cod. st 344 (Nr. 109-114) und Cod. st 424 (Nr. 234-241), in octava Cod. st 424 (Nr. 252); zu S140 Cod. st 424 (Nr. 264-266); zu S143 Cod. st 344 (Nr. 153-154) und Cod. st 423 (Nr. 96-99).

21 In den volkssprachlichen Predigten (aber auch im lateinischen Werk mit über achtzig Sermones) sind die Feste der virgines sanctae gemessen an ihrer Bedeutung in den Kalendarien oder den gedruckten Musterpredigten der Zeit deutlich überrepräsentiert: Cod. st 451: Maurilius, Petronilla, Appolonia (S96), Kunigunde (S132), Margareta (S47), Von der aufdeilung der zwelffpoten (S97), Joseph (S129), Laurentius (S56), Matthaeus (S67). Cgm 4337: Walpurga, Sebold, Mariae Empfängnis (S5), Barbara (S98), Lucia (S7), Mariae Heimsuchung (S145). Cgm 4438: Martha (S148), Dorothea (S115), Anna (S94), Mt 8,2 (T13), Martha (S148), Otilia, Appolonia (S96), Ursula (S97), Prisca, Monica, Dorothea (S115), Juliana, Elisabeth (S82). Cgm 371: Thomas (S8), Anna (S94), Magdalena (S49), Gertrude.

22 „Der Hauptaltar [...] ist dem Kirchenpatron Johannes d. Täufer geweiht.“ Die weiteren Altäre sind folgendermaßen gewidmet: Nikolaus, Anna, Jungfrauen, Georg, Willibald, Martin, den vier Kirchenlehrern, den vierzehn Nothelfern, Luzia und Othilie, Augustinus, Dreikönige, Stephanus und Laurentius, Johannes d. Evangelisten, Michael, Clemens, der Schmerzhaften Mutter und der Dreifaltigkeit. Höcherl, S. 26.

23 Vgl. Anm. 5, 7 und 8. 
meinschaften empfohlen, die in besonderer Weise Maria zum Dienst verpflichtet waren: ${ }^{24}$

Ecclesiis universis, præsertim dedicatis in memoriam beatissimae, \& gloriosæ semper Virginis Mariæ. Unus ex zelatoribus suis indignus, volens diem in honorem Virginis ejusdem, atque justi Joseph sponsi sui, testis ac custodis sui celebriter venerari. ,Pertransibunt plurimi‘ (juxtà verbum Danielis.XIII.4.), \& multiplex erit scientia.' Placuit itaque divinæ sapientiæ (quæ ,attingit à fine usque ad finem fortiter, \& disponit omnia suaviter` Sap.VIII.I.) inclinare novissimis temporibus istis corda multorum, ut justi Joseph, \& Mariæ virginale (sicut Hieronymus appellat) conjugium esse venerandum solemni cultu Ecclesiæ doceret, atque promoveret sua devotio. ${ }^{25}$

Mit seinem lateinischen und volkssprachlichen Euvre verdeutlicht Balthasar Boehm diesen Verehrungszusammenhang in idealer Weise, findet sich doch im ,Repertorium der lateinischen Sermones des Mittelalters von 1350 bis 1500` kein weiteres Predigtœuvre, das zu beinahe allen in den Kalendarien der Zeit verbreiteten Marienfesten Muster ${ }^{26}$ und darüber hinaus noch drei Josefspredigten ${ }^{27}$

24 Dies dürfte auch für das Augustiner-Chorherrenstift Rebdorf zutreffend gewesen sein, da wohl ein Patrozinium bestand, vgl. Anm. 22.

25 Gerson: Epistola (Du Pin IV, Sp. 732D-733A); vgl. Seitz, S. 201.

26 Wie ein Vergleich mit der von Schneyer erfassten Überlieferung zeigt: $\mathrm{Zu}$ den Anlässen In purificatione b. Mariae (S21), In adnuntiatione b. Mariae (S28), In adsumptione b. Mariae (S59) und In nativitate b. Mariae (S65) sind nach Kenntnisstand Schneyers (CD-ROM) 204, 237, 264 und 199 Predigten überliefert, zum Anlass In conceptione $b$. Mariae (S5) nur noch 106, zu De visitatione Mariae (S145) 67 und zu In compassione Mariae (S140) nur acht bzw. zu De praesentatione Mariae ad templum (S143) nur sieben. Die Predigten zu S140 stammen von Bernhardinus de Bustis, Johannes Stekna und Johannes Hus, die Predigten zu S143 von Hieronymus von Prag, Johannes Keck, Johannes II. de Jenzenstein und Udalricus Kaegerl. Die Überlieferungslage erklärt sich aus der in den verschiedenen Diözesen und Orden zeitversetzten Einführung bestimmter Marienfeste wie S5, S140 und S143. Weder dem Umfang nach noch im Hinblick auf die Vollständigkeit der Marienfeste gibt es in der spätmittelalterlichen Überlieferung, nach bisherigem Kenntnisstand, eine Parallele zu Boehms Werk. Selbst Augustinus Holzapfler, der mit 86 von Schneyer registrierten Sermones - zu S5 (6), S21 (12), S28 (13), S59 (25), S65 (16), S145 (14) - nach Boehm zu den produktivsten Verfassern von Marienpredigten gehört, deckt nicht die gleiche Anzahl an Festanlässen ab. Um das spezielle Interesse Holzapflers und Boehms zu verdeutlichen: Von Bernhardinus de Bustis stammen laut Schneyer 34 Marienpredigten, von Johannes Herolt (vorbehaltlich der Verfasserfrage) 27 Sermones.

27 Die lateinischen Josefspredigten Boehms sind in die chronologische Ordnung des Musterpredigtbands Cod. st 423 eingefügt, demnach datiert Boehm das Josefsfest auf den 19. März und folgt damit den Vorgaben des Missale Eystetense, vgl. Anm. 47. Die Perikopen lauten für die erste Predigt (Nr. 237) Spr 10,1, für die zweite Predigt (Nr. 238) Gen 41,40 und für die dritte (Nr. 239) Mt 1,20. Schneyer (CD-ROM) registrierte zwei Predigten zu S129 (bzw. T5); eine von Bernhard von Siena (Nr. 161) und eine von Robertus Caracciolo (Nr. 142). 
enthält. Wenn es im Folgenden nun aber nicht um Maria in einem Hymnus oder einer Sequenz geht, sondern um Boehms volkssprachlichen Traktat, der das Fest des hl. Josef propagiert, so ist dies dennoch als Beitrag zur Wirkungsgeschichte der Verehrung der Mutter Gottes und zur Entwicklungsdynamik der spätmittelalterlichen Liturgie zu verstehen; lieferte doch die marianische Festpraxis, insbesondere auch die Feier der Unbefleckten Empfängnis, wie zu zeigen sein wird, einen entscheidenden Beitrag zur Aufwertung des Kults des hl. Josef. ${ }^{28}$

\section{Boehms Traktat zum Gedenktag des hl. Josef}

Der Text Von dem helligen vatter Joseph könnte, da er der „Verkündigung religiöser Heilsbotschaft[en]“29 dient, als Predigt bezeichnet werden. Dies legt auch der Überlieferungszusammenhang in der Sammelhandschrift Cod. st $451^{30}$ der Universitätsbibliothek Eichstätt mit weiteren Sermones des AugustinerChorherrn nahe, jedoch nimmt diese Kompilation im Euvre eine Sonderstellung ein. So wird hier die Fortsetzung der Lektüre angekündigt (Nvn so wollen wir die deilung dis buchs fleiß thvn, ob wir morgen obtwaß sagen von dem lobe des groß helligen vatters sant Ioseph), ${ }^{31}$ was singulär in Boehms Predigten ist, also nicht den üblichen Formulierungen zur Kennzeichnung der Aufführung entspricht, wie Dise wort [...] werden hewt gelesen ${ }^{32}$ oder Dise wort [...] an disem hewtigen fest. ${ }^{33}$ Freilich wäre die obige Ausführung auch in einer längeren Lesepredigt denkbar, doch dürfte der Begriff buch auf eine wesentlich umfangreichere und zur Fortsetzung konzipierte lectio verweisen (bspw. von der Vigil bis zur Oktav des Fests), worauf auch die Datierung Deo gracias 1520 in octava die sancti Ioseph ${ }^{34}$ schließen lässt. Ob dies bereits auf eine geänderte Festpraxis im Chorherrenstift Rebdorf hinweist oder nur dem frommen Wunsch, das Josefsfest mit Oktav zu feiern, Rechnung trägt, ist nicht mehr zu erschließen. Als Rezipien-

28 Eine ähnliche Aufwertung erfährt in der Zeit schließlich auch das Fest der hl. Anna. So weist Dörfler-Dierken (S. 73) darauf hin, dass „[i]n die meisten Diözesan- und Ordenskalender [...] das Annenfest erst nach 1481 eingeführt worden“" sei.

29 Hasebrink, H.-J. Schiewer, S. 151.

$30 \mathrm{Vgl}$. Anm. 16.

31 Joseph, Cod. st 451 (Nr. 9), fol. $158^{\text {ra }}$.

32 Von sant Thomas dem appostelein ein predig, Cgm 371 (Nr. 1), fol. $41^{\mathrm{r}}$.

33 Von vnser liben frawen entpfenckniß, Cgm 4337 (Nr. 3), fol. $33^{r}$.

34 Joseph, Cod. st 451 (Nr. 9), fol. $188^{\text {va }}$. 
ten können, da es sich um einen volkssprachlichen Text handelt, Chorherren und Laienbrüder vermutet werden. Dass es sich um eine Gemeindepredigt handelt, ist wegen der Länge, vor allem aber aufgrund der erörterten Fragen unwahrscheinlich. Auch geht der Kompilator über das in den Artes Praedicandi diskutierte prädikable Wissen hinaus, indem er quaestiones traktiert, die üblicherweise, d. h. gemäß den Predigtlehren, nur dann in einer volkssprachlichen geistlichen Ansprache zu erörtern seien, wenn Irrglauben begegnet werden müsse. ${ }^{35}$ So lässt Boehm bei seinen Ausführungen besondere Vorsicht walten:

Ich mein ich sag recht, wer es anders, so wolt ich schweigen oder das wider ruffen, daß ich itzund sagen will. Also sag ich, ich halt das, so got der almechtig het gewolt vnd geordenirt, das sein liber sun Ihesus solt geparn worden sein in diser werlt von mans sammen, so halt ich das, das got het do zu auserwelt Ioseph zu einem vatter, wie er hot auß er welt Mariam zu einer mutter. ${ }^{36}$

In diesem Zitat wird die quaestio ${ }^{37}$ in eigentümlicher Weise berührt, ob die Prophezeiung, ${ }^{38}$ dass der Messias aus dem Geschlecht Davids hervorgehen werde, erfüllt worden sei. Wenn Maria durch den Hl. Geist empfing, ist dann Josef überhaupt als Vater Jesu anzusehen? Praeterea, impossibile est unum hominem duos patres habere. ${ }^{39}$ Boehms Ziel ist es nicht, an Dogmen zu rütteln, sondern die besondere Ehrwürdigkeit Josefs als pater familias zu illustrieren und gleichzeitig Wissen über die Genealogie der Hl. Familie zu vermitteln. Die Positionen werden nach scholastischer Manier referiert:

35 Siehe Roth, S. 174.

36 Joseph, Cod. st 451 (Nr. 9), fol. 159 ${ }^{\text {rb }}$. Vgl. auch im Anschluss an die Ausführungen zur Genealogie Josefs und Marias: Noch merck das, du leser diser wort, daß sag ich, dise wort redt ich nit ver war, sunder vß duncken vnd andacht vnd auß ausczugen vil bucher, hab ich geirt so wider ruff ich das (ebd., fol. $161^{\mathrm{va}}$ ).

37 Vgl. Thomas de Aquino: S. th. III, q. 31: Deinde considerandum est de ipsa conceptione salvatoris. Et primo, quantum ad materiam de qua corpus eius conceptum est; secundo, quantum ad conceptionis auctorem; tertio, quantum ad modum et ordinem conceptionis. Circa primum quaeruntur octo. Primo, utrum caro Christi fuerit sumpta ab Adam. Secundo, utrum fuerit sumpta de David. Tertio, de genealogia Christi quae in Evangeliis ponitur. Quarto, utrum decuerit Christum nasci de femina quinto, utrum fuerit de purissimis sanguinibus virginis corpus eius formatum. Sexto, utrum caro Christi fuerit in antiquis patribus secundum aliquid signatum. Septimo, utrum caro Christi in patribus fuerit peccato obnoxia. Octavo, utrum fuerit decimata in lumbis Abrahae.

38 Num 24,17: Videbo eum sed non modo intuebor illum sed non prope orietur stella ex Iacob et consurget virga de Israhel et percutiet duces Moab vastabitque omnes filios Seth.

39 Thomas de Aquino: S. th. III, q. 31, a. 3, arg. 2. 


\begin{abstract}
Merck, eß spricht Damascenus lib. 4, c. 6: Maria, die hellig mütter vnd junckfraw, sey geporn von David durch Nathan, Ioseph aber von David durch den Salomon. Wan Dauid vnter vil sünen het er zwen sün, Nathan prophetem vnd Salomon, der wurd der aller weisst künig, als stet geschriben an dem ersten puch Paralippomenom an dem tritten capitel vnd als vns sagt Lyra vber Lucam. Wie wol die weisen der hebreischen mit einikeit haben gehalten auß der schrifft, das Cristus geporn solt werden von Dauid. Etlich doch auß in haben gemeint, er solt werden geporn von Dauid durch de sün Nathan, wmb der groß wirdikeit seiner hellikeit vnd seiner prophecey, die der selbig Nathan durch die eingebung des helligen geistes hot auß gesprochen. Etlich aber haben geschaczt, das Cristus, der war messias, solt geporn werden von Dauid durch sein sün Salomonem vmb vrsag der kuncklichen wirdikeit vnd ere der grossen weisheit. Aber noch der rechten warheit ist Cristus entsprungen vnd geporn von allen peiden vnd durch alle peiden, daß ist durch Salomonem vnd Natham, ped süne Dauid. Aber anders vnd anders, wan durch Salomonem ist er kumen durch die naturlich linien der gepurt, aber durch Nathan ist er kummen noch der geseczlichen linien der gepurt..$^{40}$
\end{abstract}

Erst auf dieser Grundlage - weitere Erläuterungen zu Melchi oder Panthera (Barpanthera) können wir überspringen - lässt sich schließlich Marias Verwandtschaft mit Josef und damit die gesetzliche und natürliche Abstammung Christi in direkter Linie von David über Maria (fleischlich) sowie von David und Salomon über Josef (gesetzlich) begründen. Wie Boehm in Übereinstimmung mit der Doktrin ${ }^{41}$ erläutert, bestehe die Lösung der Frage nach der Vaterschaft des Josef darin, nach mosaischem Recht zwischen der fleischlichen und der gesetzlichen Abstammung zu unterscheiden: Dem Gesetz nach (Dtn 25,6) sei Jesus Josefs Sohn, wie auch Josef nur dem Gesetz nach Sohn des Eli gewesen sei. ${ }^{42}$ Wie er erläutert, sind damit aber beide im obigen Abschnitt dargelegte Annahmen über die Abstammung Christi kompatibel:

$\mathrm{Nu}$ merck, als do vns sagen vnd beweisen die schrifft, so man recht auß rechent, so find man, daß Maria vnd Ioseph sein gefrevndt gewest noch dem pluet bey dem segsten grad in der frevntschafft, in dem die ee ist erlewbt. Es spricht Matheus: Mathan hot geporn Iacob. Do mocht yemant claffen, also anders spricht Lucas an dem tritten capitel, wan Mathat hot geporn Heli vnd Heli hot geporn Ioseph. Do spricht Lyra, das Mathat vnd Matan sein kümen von Dauid, aber Mathat durch Nathan, der do was ein sün Dauid. Mathan aber kumpt von Dauid durch den Salomon vnd die zwen Mathat vnd Mathan hetten ein frawen noch eynander mit nomen Hesta. Vnd Hesta entpfing von dem Mathan, entpfing Iacob, vnd dor noch entpfing si von Mathat den Heli, als das Iacob vnd Heli waren bruder von der mütter, aber si komen von zweyen prudern, die von Dauid abstigen in der gepurt, einer durch Nathan, einer durch den Salomon. Nun es geschae, das Heili nam

\footnotetext{
40 Joseph, Cod. st 451 (Nr. 9), fol. 160 ${ }^{\text {ra-b }}$.

41 Vgl. Catalogus Sanctorum III,48.

42 Joseph, Cod. st 451 (Nr. 9), fol. 160 ${ }^{\text {rb }}$.
} 
ein weip noch dem gesecz Moisi vnd starb oen kind vnd samen, dor vmb Iacob, sein pruder, müst nemen seins to̊ten pruders weip, vnd must auf wecken den samen an seins pruders stadt, vnd gepar den selligen vnd helligen Ioseph. Also was Ioseph ein naturlicher sun des Iacobs, also meint es Matheus in seinem ewangelio, aber er was ein sun auch Heli noch dem gesecz, nit noch der natur, also hot in gemeint Lucas in seinem ewangelio, vnd si haben pet ein rechte meynung, Lucas vnd Matheus. ${ }^{43}$

Über die Leviratsehe wäre somit die direkte Abstammung Josefs von Salomon (gesetzlich) und von David (fleischlich) sowie die Verwandtschaft zwischen Maria und Josef (fleischlich) gesichert. Obwohl oder gerade weil Josef nicht der natürliche Vater Jesu ist, spielt die Genealogie - auch im Hinblick auf die Leviratsehe „Jakob[s] mit der Witwe seines Stiefbruders Eli“, über die Josef „die beiden Linien der Davidssöhne wieder zusammen[führt]“44 - eine entscheidende Rolle, um aus dieser Abstammungsgeschichte auch Marias Zugehörigkeit zum Stamm Davids zu begründen. ${ }^{45}$ Genealogischen Beziehungen geht Boehm mit großem Interesse nach, was der im Spätmittelalter wachsenden Bedeutung der Hl. Familie und aller Verwandten des Herrn in der Liturgie entspricht. ${ }^{46}$ Doch bilden dies die für Boehm maßgeblichen Liturgica der Diözese, der Windesheimer Kongregation sowie der Augustiner-Chorherren Rebdorfs nicht ab. Überhaupt liefert die Josefsliturgie weder dem Umfang noch dem Inhalt nach Anstöße für ein über 64 Folioseiten tragfähiges Konzept. ${ }^{47}$ Dennoch sind gerade

43 Joseph, Cod. st 451 (Nr. 9), fol. $160^{\text {va }}$.

44 Wucherpfennig, S. 56-57.

45 Damit knüpft Boehm an die Tradition der Väter an, „die Genealogie“ zu erörtern, wozu die Evangelisten Anlass bieten, da sie Jesu Abstammung bei Josef ansetzen. Zu den Aussagen der Väter vgl. Seitz, S. 24-29.

46 Vgl. De sancto Joseph, AH 19, S. 164-165, Nr. 284; hier S. 164, Str. 1: O veneranda trinitas, / Jesus, Joseph et Maria, / Quam conjunxit divinitas / Caritatis concordia.

47 Allein das Eichstätter Messbuch (nur für den Gemeindegottesdienst verbindlich) weist ein Formular auf, doch bietet dieses keine spezielle, d. h. in besonderer Weise ausgestaltete Liturgie zum Fest des hl. Josef an. Vgl. Missale Eystetense, fol. CCLXXIIII ${ }^{\mathrm{ra}-\mathrm{rb}}$. Das Fest De s. Josepho wird im Kalender des Missale Eystetense nicht genannt, im Prolog (fol. $6^{v}$ ) findet sich der Verweis: De sanctis Ioseph et tribus Regibus et cautele circa pericula misse cclxxiii. Oratio: de sancto Ioseph nutritore domini. Beati Ioseph patriarche tui presidiis domine muniamur: qui et temporalem vnigeniti tui fideliter educauit infantiam et eiusdem virgini genitrici, virgineus ipse custos et testis esse meruit et minister. Per eundem. Secreta: Hec oblatio domine ad salutem mentis et corporis eius nobis intercessione proueniat: per quem temporaliter celi panis et pastor est pastus, et cibus ipse cibatus est angelorum. Per eundem. Complenda: Illius quesumus domine interuentu ecclesie tue deuotio foueatur, cuius immaculate virginitati, beate Marie coniugata virginitas sanctospiritu fecundata mundo peperit saluatorem dominum nostrum Iesum Xpm filium tuum. Qui tecum. Es handelt sich wohl um eine gekürzte Fassung des Regensburger Formulars (1434), Liber missalis secundum chorum ecclesiae maioris Ratisponensis 1479 (Clm 2506, fol. 339), 
im Josefstraktat die Verweise auf die Liturgie von besonderer Relevanz für den argumentativen Aufbau - allerdings steht dabei die Marienliturgie im Vordergrund, in der immer schon Josef, bspw. über die Perikopen Mt 1,188 oder Lk 1,26$27^{49}$ oder auch zahlreiche Hymnen, ${ }^{50}$ präsent ist. Die Perikopen belegen damit einen in Liturgie und Predigtpraxis stets möglichen unmittelbaren Verehrungszusammenhang, entweder über die Genealogie (nach Matthäus) oder über die Jungfräulichkeit Mariens (nach Lukas), für die Josef der Garant war. ${ }^{51}$ Diese Schriftzitate, die auch in der Diskussion um die immaculata conceptio und der Rechtfertigung des Annenkults von Bedeutung sind, ${ }^{52}$ bieten Boehm zentrale argumenta für eine Aufwertung des Josefsfests.

abgedruckt bei Seitz, Anhang II, S. 341-342. Weitere für Boehm relevante liturgische Vorgaben, sei es von den Augustinern oder von den Windesheimern, konnten nicht ermittelt werden.

48 Siehe Boehms Predigt In conceptione b. Mariae, Cod. st 423 (Nr. 128) zu Mt 1,1.

49 Siehe Boehms Predigt In adnuntiatione b. Mariae, Cod. st 345 (Nr. 100) und Cod. st 423 (Nr. 245), entsprechend den Vorgaben des Missale Eystetense, fol. CCVIII ${ }^{\mathrm{rb}}$ (EVA). Sowohl auf Grundlage der vorgegebenen lectio wie der antiphona als Perikope wählbar, vgl. Marbach, S. 423: „Lc 1,26.27. Missus est Gabriel Angelus ad Mariam virginem desponsatam Joseph. Ant. I. ad Vesp. et Laud. in Annuntiatione B.M.V.“

50 AH 2, S. 80-81, Nr. 109; hier S. 80, Str. 4; AH 4, S. 39-40, Nr. 52; hier S. 40, Str. 5; AH 4, S. 49-50, Nr. 72; hier S. 49, Str. 5; AH 5, S. 70-72, Nr. 20; hier S. 70, Str. 2; AH 8, S. 75, Nr. 92; hier Str. 2a; AH 10, S. 81-82, Nr. 96; hier S. 82, Str. 10a; AH 10, S. 94-95, Nr. 118; hier S. 94, Str. 3b; AH 10, S. 97-98, Nr. 123; hier S. 97, Str. 2b; AH 12, S. 54, Nr. 86; hier Str. 2; AH 12, S. 54-55, Nr. 87; hier S. 54, Str. 1; AH 12, S. 56-57, Nr. 89; hier S. 56, Str. 2; AH 17, S. 34-37, Nr. 8, hier S. 35, Str. 2 (Responsoria); AH 23, S. 57-58, Nr. 84; hier S. 57, Str. 4; AH 48, S. 128-131, Nr. 107; hier S. 128, V. 25-26; AH 54, S. 291-294, Nr. 189; hier S. 292, Str. 16.

51 Vgl. Anm. 8.

52 De Dieu, S. 29: „D’ailleurs, sans prétendre que le titre de mère de l'Immaculée ait été l'unique raison du culte rendu à sainte Anne - ce serait pur artifice, car plusieurs causes y contribuèrent - nous allons constater que la qualité de Mère de la Vierge Immaculée en a été la raison principale. Fait d'autant plus remarquable que le titre de Mère de la Mère de Dieu eût pu être pris davantage en considération, puisque la Maternité divine de Marie fut objet de foi explicite dès l'origine, tandis que l'Immaculée-Conception demeura longtemps de foi implicite.“ Als „notwendige Folge der Verehrung der unbefleckten Empfängnis Marias“, wie es Kleinschmidt (S. 162) und De Dieu (S. 16-39) bewerten, betrachtet Dörfler-Dierken (S. 46 u. ebd., Anm. 3) den Annenkult nicht. Sie bezweifelt die Bedeutung der „feinen Distinktionen der Theologen“, doch konstatiert sie selbst (ebd.): „Sämtliche in diesen Jahren [an der Wende vom 15. zum 16. Jh.] entstandene und verbreitete Texte vertreten die Auffassung von einer besonderen Auszeichnung der Gottesmutter im Sinne einer vorgeburtlichen Heiligung beziehungsweise einer schon im Moment der Empfängnis wirksamen Heiligung, nicht aber die Lehre der erst 1854 als Dogma fixierten immaculata conceptio.“ Doch stellte Sixtus IV. ja bereits 1477 (Denzinger, Hünermann, Nr. 1400) fest, dass es angeraten sei, das Fest zu feiern. Vgl. Anm. 59. Auch 


\title{
2 Die Immaculata-Frage als Präzedenzfall
}

Das Fest Mariä Empfängnis wurde im Spätmittelalter zwar in vielen Diözesen gefeiert, ${ }^{53}$ doch bestand über die Immaculata-Frage bis 1854 Uneinigkeit; erst dann wurde die Unbefleckte Empfängnis, d. h. die Empfängnis Mariens frei von der Erbsünde, von Pius IX. zum Dogma erklärt. ${ }^{54}$ Besonders im Spätmittelalter „war das Thema Gegenstand scharfsinniger Disputationen, aus denen sich im Laufe der Zeit heftige Kontroversen zwischen den Schulen entwickelten“. ${ }^{55}$ Boehm weist in seiner Predigt Von vnser liben frawen entpfenckni $\beta$ auf die Problematik der ungeklärten Frage einer Teilhabe Mariens an der Erbsünde hin und wird schließlich in seinem Josefstraktat auf diese Kontroverse bezugnehmend Konsequenzen für die Verehrung des hl. Josef fordern. In seiner volkssprachlichen Marienpredigt fasst er den aktuellen Stand der Diskussion um das Fest Conceptio Mariae zusammen. Selbst wird er keine Position explizit verteidigen, obgleich die Anlasspredigt, gemäß den für ihn verbindlichen liturgischen Vorgaben, ${ }^{56}$ nur eine zustimmende Haltung zulässt:

\begin{abstract}
Nvn seitemal der prvn, Ihesus Cristus, der vrsprunck aller gutikeit, tugent, sussikeit, weisheit, reinikeit vnd sellikeit ist entsprungen vnd aüsgeflossen auß der helligen iunckfrawen Maria. So ist daß vns ein anzeigung, daß si sey gewesen die aller reinst vnd lawter vnd schon oon alle sund dechlich, dotlich vnd auch oen alle erbsund. Wie wol fil gelerten sprechen, si geporn vnd entpfangen sein in erbsundt vnd legen fur vil vrsag vnd auch, als ich nit anders weiß, dan es sey auß des pobst gewalt hoch verpoten, daß niemant sol sprechen oder halten festickligen, daß si sey geporn oen erb sund. Ader wider vmb, daß si sey geporn oen erb sundt dannoch, so halten vil mer doctores in einer gutigen meinung, daß si got hab vorkummen vnd behut vnd behalten vor der erbsund. ${ }^{57}$
\end{abstract}

Ausschlaggebend für die Durchsetzung des Fests war trotz des päpstlichen Vorbehalts und unabhängig von der Frage, wie groß die Lager von Befürwortern

scheinen sich Annabruderschaften im Zusammenhang mit Marienbruderschaften entwickelt zu haben; vgl. Schnurrer, S. 87.

53 Grotefend, s. v. ,Marie Conception‘. Auch sind frühe deutsche Predigten zu S5 von R. Schiewer nicht ermittelt worden.

54 Vgl. Lohse, S. 202.

55 Horst, S. 1.

56 Boehm berücksichtigt bei der Konzeption seiner Musterpredigten die liturgischen Vorgaben der Augustiner-Chorherren, die der Windesheimer Kongregation sowie die der Diözese Eichstätt. Dies ergibt sich aus dem Anschluss des Stifts an die Kongregation (1458) sowie daraus, dass die Rebdorfer Stiftskirche zugleich als Gemeindekirche fungierte. Vgl. Falch, S. 124.

57 Von vnser liben frawen entpfenckniß, Cgm 4337 (Nr. 3), fol. $34^{r}$. 
oder Gegnern waren, die spätmittelalterliche Glaubenspraxis, ${ }^{58}$ worauf Boehm in der Argumentation hinweist:

Auch haben die pebst geben grossen ablaß zu disem fest, gleich als der aplas lavt vnd geben ist an vnsers hern leichnams dag. Man feiert keinß helligen entpfenckniß dan allein der iunckfrawen Maria als hewt vnd auch deß hern Ihesu Cristi in der fasten, do der engel Gabriel von himel rab kam vnd gruest die mutter gottis Maria vnd sprach: Aue Maria etc. ${ }^{59}$

Durch die Anerkennung der Nützlichkeit des Festes für das Seelenheil durch Ablässe ist die Festpraxis hinreichend legitimiert. Der Augustiner-Chorherr kann freilich in Ermangelung geeigneter Autoritäten (aus Patristik und Bibel) keine Belege für die Unbefleckte Empfängnis Mariens vorbringen. Und so lassen sich nur argumenta und dicta anführen, die die besondere Auserwähltheit Mariens als dei genetrix belegen bzw. darauf schließen lassen, wie bspw. Lk 1,3560 oder auch, trotz anderer Auffassung in der Immaculata-Frage, Bernhard von Clairvaux. ${ }^{61}$ Boehm verweist letztlich auf die unentschiedene Diskussion, auch wenn er sich den Befürwortern anschließt:

58 Horst, S. 2-3: „Durch eine intensive Predigttätigkeit in den Jahrzehnten nach dem Basler Konzil wuchs beim Volk der Glaube an die unbefleckte Empfängnis Mariens in einem bisher unbekannten und für die Theologen folgenschweren Ausmaß." Vgl. De Dieu, S. 36.

59 Von vnser liben frawen entpfenckniß, Cgm 4337 (Nr. 3), fol. 35".

60 Ebd., fol. $35^{\mathrm{r}-\mathrm{v}}$ : Aber got der almechtig hot geert sein libe mvtter Maria, wan ee er dem leib Marie ein guß die helligen sel, hot er iren leip gereinickt von aller poeser neigvng vnd vergifftung von Ademßfal. Vnd vber daß hot got si gehelligt mit grossen gnaden deß helligen geistes vnd dor noch hot er dem leib Marie ein gossen die helligen sel vnd hot si also behut vor der erbsund. Hellig must sein der leip Marie vnd die pruest Marie, die do solten geperen, neren vnd seigen den sun deß ewigen kvnigs von himel. Als man list Ieremie primo in dem alten testament ist sant Ieremias geheligt worden in mütter leib, ee er wurd geporn. Auch als man list Luce primo[,15], sant Iohannes wurd erfuldt mit dem helligen geist, do er noch was in mvtter leib. Vnd sant Ieremias vnd sant Iohannes sein allein gewest propheten vnd knecht gottes vnd sein geheligt in mvtter leib. Wie mer daß ist vns billig zu gleiben vnd gutlichen zu meinen, daß got sein hellige, aller libste mutter Maria hab in mvtter leib, si vber alle helligen geert vnd gehelligt. Hot got also geert vnd gehelligt sein knegt, wie vil mer hot er geert die hochwirdigen kunigen vnd sein libe mütter. Wan Maria ist vn aussprechlich hellig an leib vnd sele, dor vmb hot got offenpar thon den cristen lewten, vf daß man ere vnd feire die reine entpfenckniß seiner mütter Marie.

61 Ebd., fol. $35^{\mathrm{v}}$ : Etlich probieren, daß si sein geporn o̊n erbsund, etlich sagen anders, von den wil ich schweigen vnd wollens alls got entpfel. Daß wissen wir wol, wan die junckfraw Maria ist aller ern wirdig, wan got hot si auserkorn vnd geert vber alle creatur. Wan eß spricht Bernhardus: O Maria, als dein svn Ihesus Xpus vnser her ist benedeit vber alle mender, also bistu gelobt vnd gebenedeit vber alle frawen in den himeln vnd auf erden. So wird Bernhard von Boehm als Autorität vereinnahmt, ohne dass entschieden werden kann, ob der Augustiner- 


\begin{abstract}
Nvn wie wol Maria ist entpfangen von mendlicher mit wirckvng vnd mendlichem samen in dem leib sant Anne, ir mutter, wie ander lewt, dannoch hot got geert sein mütter, als etlich doctores halten vnd etlich do wider sein: Hot got geert sein schon mvtter Maria, also wan er hot si, als ich auch gutlich mein vnd nit wil festicklich daß verbar halten, vff daß ich nit vngehorsam sein dem pebstlichen gepot. ${ }^{62}$
\end{abstract}

Das gepot steht dem Glauben an die Unbefleckte Empfängnis Mariens nicht im Wege, nur die Verteidigung einer Position gegen die andere ist untersagt. Schließlich hat sich das Fest bereits in vielen Diözesen, Orden und Kommunitäten etabliert, wenn auch in unterschiedlicher Ausprägung. ${ }^{63}$ Der AugustinerChorherr lässt also alle Vorsicht walten. Trotzdem markiert er seine Position durch die Wahl des Predigtthemas, das uns wohl nachdrücklich auf das Festgeheimnis hinweisen soll.

Für die deutsche Predigt Von vnser liben frawen entpfenckniß wählt Boehm in Abweichung von den Perikopen der lateinischen Musterpredigtsammlung, die streng an den liturgischen Vorgaben ausgerichtet sind, ${ }^{64}$ den eher für einen Commune-Anlass zu erwartenden Versikel Fluminis impetus laetificat civitatem $D e i^{65}$ bzw. den zweiten Versbestandteil sanctificavit tabernaculum suum Altissimus (Ps 45,5) als Perikope. Ebenfalls unzitiert bleibt in der deutschen Predigt die Lesung Dominus possedit me initium viarum suarum antequam quicquam faceret a principio (Spr 8,22), die im Missale ${ }^{66}$ und Brevier ${ }^{67}$ vorgegeben ist und von Verfassern von Predigthilfsmitteln zum Anlass Conceptio Mariae gewählt wurde. ${ }^{68}$ Diese wird erst gar nicht erwähnt, obwohl sich das Thema Dominus possedit me ab initio ${ }^{69}$ doch auch anbieten würde, einen Beleg für Marias Geburt frei von Erbsünde zu insinuieren; schließlich hat Boehm auch zu dieser Lesung ein Muster verfasst.

Chorherr die Position des Zisterziensers kannte, vgl. Horst, S. 18. Ob und aus welchen Predigthilfsmitteln Boehm das Zitat bezog, lässt sich abschließend nicht mehr ermitteln; zur Kompilationstechnik von Boehm siehe Falch.

62 Von vnser liben frawen entpfenckniß, Cgm 4337 (Nr. 3), fol. 34v.

63 Vgl. Heal, S. 25-26. Siehe auch Anm. 48.

64 Vgl. Falch, S. 124.

65 Marbach, S. 130: „Ps 45,6. Adjuvabit eam [...] [Ps 45,5] V. Fluminis impetus [...]. Grad. in Missa Me exspectauerunt pro Virg. et Mart.“

66 Missale Eystetense, fol. CXCVII ${ }^{\text {va }}$.

67 Breviarium Eystetense, Bd. 3, fol. $208^{\text {va }}$.

68 Bspw. von Guillermus Parisiensis: Postilla, fol. XXXVIIIv: In festo conceptionis beate virginis Marie pro epistula presens lectio [Proverbia VIII] karissimus seculares legitur: que lectio principaliter exponitur de eterna sapientia que Xps est filius Marie virginis. Honor autem filii / est honor matris / et econuerso: honor matris / est honor filii.

69 Perikope der Predigt Boehms: In conceptione b. Mariae, Cod. st 423 (Nr. 127). 
Die Themenwahl Boehms akzentuiert jedoch stärker den Gedanken der vollendeten Reinheit Mariens. Denn der Ps 45,5 ist, obwohl vom Aussagegehalt vergleichbar, ${ }^{70}$ auch lyrischer als Spr 8,22 - vor allem komplementär zum Versikel Elegit eam deus et praeelegit eam. Et habitare fecit eam in tabernaculo suo. ${ }^{71}$ So wird dann nicht nur an die Erfüllung der Prophezeiung, sondern auch nachdrücklich an die Reinheit der Jungfrau erinnert. Im Zentrum der Predigten zu diesem Anlass steht schließlich das Festgeheimnis von der Geburt Jesu durch die reine Jungfrau im Hause David. Deswegen ist mit dem Verweis auf das tabernaculum suum [des Herrn] id est uterum Virginis; Maria namque stella maris interpretatur $^{72}$ wiederum die Verbindung zur Jungfrauschaft (nach Lukas) und zur Genealogie (nach Matthäus) geknüpft, die beide obligatorisch zum Predigtanlass gehören; so hält es bspw. auch der Catalogus Sanctorum: [in] [n] atiuit[ate] gloriose virginis Marie ex tribu Iuda et regia stirpe Dauid. ${ }^{73}$ Aus dieser Verknüpfung von Familienkunde und Jungfräulichkeitslob ergibt sich, wie gleich zu zeigen sein wird, ein Beweiszusammenhang: zum einen für die Abstammung Mariens, zum anderen für die Frage nach dem Status der Jungfräulichkeit des Josef. Denn so wie die Evangelisten über die Stammeszugehörigkeit Mariens schweigen und die Kirchenväter und Kirchenlehrer diese aus der Ehe mit Josef ableiten, begründen sie wiederum Josefs Jungfräulichkeit, über die ebenfalls die Hl. Schrift schweigt, mit der Virginität Mariens.

\section{Die Position Jean Gersons}

Betrachten wir die Argumentation in Gersons Marienpredigten für das Lob des hl. Josef. Auch dieser Verfasser koordinierte Marien- und Josefspredigten, auf die Boehm in seinem Josefstraktat durchgehend Bezug nimmt. Gerson beginnt sein Lob Mariä nach den liturgischen Vorgaben mit Mt 1,16: Jacob autem genuit Joseph virum Mariae de qua natus est Jesus qui vocatur Christus und überträgt die Deutung im Hinblick auf die besondere Auserwähltheit der Mutter Jesu auch auf den Hausvater Josef. Boehm greift diesen Kerngedanken - Unde, sicut laus Mariæ est laus Christi Filii sui; ita laus Joseph in præconium redundat utriusque,

70 So wählt bspw. auch Herolt (Sermones discipuli de sanctis, V) diese Perikope. Immerhin handelt es sich bei dieser Musterpredigtsammlung um die verbreitetste. Vgl. Thayer, S. 17.

71 Breviarium Eystetense, Bd. 3, fol. $255^{\text {rb }}-258^{\text {rb }}$. Purificatio Mariae. Cantus-ID: 008046.1.

72 Oddo Astensis: Expositio in Psalmos XVIIII (PL 165, 1187D).

73 Catalogus Sanctorum, VIII,51. 
Jesu \& Mariae ${ }^{74}$ - aus Gersons Predigt zur Geburt der Hl. Jungfrau Maria auf. Boehm folgt dieser Position, wodurch eine Orientierung an Marienpredigten für das Lob Josefs erfolgen kann:

Wan als got der vatter seinen sun in seiner mensch werdung hot auß erwelt die edelst vnd helligst mutter, die junkfrawen Mariam, die do waß also rein, als spricht Anshelmus, das kein reiner vnd helliger fraw vnter got mocht erdocht werden. Also wolt auch got der vatter seinen sün Ihesum ordiniern vnd zu fugen ein versorger vnd ernerer vnd ein vatter der sorg, der do wer in sulcher frumickhait vnd eren vnd hellikeit, daß keiner grosser vnd besser mogt erfünden werden in der gantzen werlt vff die selbigen zeit. Wan wie wol Cristus spricht, Mathei an dem eilfden capitel: Vnter den sünen der frawen ist niemant grosser auf erstanden dan Iohannes der dewffer. Doch was Iohannes noch nit geporn, do der hellig Ioseph nam zu der helligen ee die schonen junckfrawen Mariam. ${ }^{75}$

Boehm übersetzt hier Mt 11,11 (non surrexit inter natos mulierum maior Iohanne Baptista qui autem minor est in regno caelorum maior est illo), also die Stelle, die analog zum Beginn des Lukasevangeliums die besondere Dignität des Johannes belegt. In Eichstätt wurde Erit enim magnus coram Domino et vinum et sicera non bibet et Spiritu Sancto replebitur adhuc ex utero matris suae (Lk 1,15) freilich In vigilia natiuitatis Iohannis baptiste ${ }^{76}$ gelesen. Gerson zufolge sei der lectio aber ebenfalls zu entnehmen, dass nicht nur Johannes im Mutterleib geheiligt wurde, sondern eben auch Josef:

Nun es spricht Iohannis Gerson: Maria die iunckfraw ist in mütter leib gehelligt worden, auch der hellig Ioseph, als Ieremiaß vnd Iohannes Baptista, als man singt vnd list in dem helligen ampt, das zu Iherusalem ist worden gemacht von dem helligen Ioseph. ${ }^{77}$

Boehm paraphrasiert hier Gerson, der freilich im Lateinischen differenzierter operiert und graduale Abstufungen in Hinblick auf den jeweiligen Anteil oder Nicht-Anteil an der Erbschuld von Maria und Josef berücksichtigt. Doch geht es beiden Verfassern nicht um diese quaestio, sondern darum, die besondere Stellung Josefs vor Gott zu begründen.

74 Gerson: Sermo de nativitate (Du Pin III, Sp. 1346B).

75 Joseph, Cod. st 451 (Nr. 9), fol. $157^{\text {rb }}$.

76 Missale Eystetense, fol. CCXIIII ${ }^{\text {ra-rb }}$.

77 Joseph, Cod. st 451 (Nr. 9), fol. $172^{\text {rb }}$. 


\begin{abstract}
Maria (de qua natus est Jesus) sicut fuerat in utero sanctificata priusquam nasceretur, ita de Joseph virginali viro suo pia credulitate credi potest, quamvis non omninò similiter. Potest forsan hæc dissimilitudo notari in hoc, quòd Joseph post originale contractum sanctificatus est in utero Baptismo flaminis, sicut Joannes Baptista, \& aliorum plurimi. Sic enim in officio Jerosolymitano de Joseph composito contitinetur, \& ex præmisso quadruplici principio sequi videtur. ${ }^{78}$
\end{abstract}

Der Bezug zur liturgischen Tradition Jerusalems verleiht der Theorie von der Gnade Josefs aufgrund der Altehrwürdigkeit des Ritus besonderes Gewicht. ${ }^{79}$ Die Aussage hat hier den Status eines argumentum, ist doch die in Liturgie gegossene Exegese von der höchsten Autorität approbiert; darauf weist Boehm auch in seiner Predigt über die Geburt Mariens hin. ${ }^{80}$ Zwar bedürfte es nach der Feststellung, dass das Lob Mariens auch für Josef in Anspruch zu nehmen sei, schon gar nicht mehr dieses Belegs, doch wird diese Aussage so noch einmal unterstrichen und auf eine liturgische Parallele zwischen Josef und Maria von alters her hingewiesen. Die Übertragung der Textstelle Lk 1,15 in der Jerusalemer Liturgie für das Fest des hl. Josef ist dabei nur konsequent, ist doch die Passage bereits genutzt worden, um die Feier der Geburt Mariä zu begründen..$^{81}$ Diese Übertragung hat zwar in der Marienliturgie keinen expliziten Niederschlag gefunden ${ }^{82}$ doch bildete Augustinus' Erklärung, dass von einer Abstufung der Gnadengaben auszugehen sei, die Johannes der Täufer und Maria empfangen hätten, wohl eine wesentliche Grundlage für die Tolerierung der Festpraxis. Schließlich sei es vernünftig anzunehmen, dass, wenn Jeremias und Johannes der Täufer besonders von Gott geehrt wurden, dies auch, und eben mehr, für die Hl. Jungfrau angenommen werden müsse. ${ }^{83}$ Trotz des Streits über die Frage, ob Maria bereits frei von der Ursünde von der hl. Anna empfangen oder erst im Mutterleib geheiligt wurde, gab die liturgische Praxis aufgrund des Fehlens einer klaren Festlegung keinen Anlass, diese Grauzone zu beseitigen.

Ohne Augustinus zu zitieren, greift Boehm in seinem Traktat auf die augustinische Argumentation zurück ${ }^{84}$ und überträgt diese auf Josef:

78 Gerson: Sermo de nativitate (Du Pin III, Sp. 1349C).

79 Schließlich ging Boehm von der Einsetzung der Liturgie durch Christus und die Apostel aus (vgl. Die ander predig von sant Thoma appostel, Cgm 371 [Nr. 2], fol. 47v), die dann weiter ausgebaut wurde. Siehe dazu Lentes, S. 336.

80 Von vnser liben frawen entpfenckniß, Cgm 4337 (Nr. 3), fol. 35v.

81 Vgl. Preuss, S. 199.

82 Vgl. Horst, S. 13.

83 Vgl. ebd., S. 12.

84 Siehe auch Anm. 60. 
Wan der her Ihesus Cristus, der do ist die ewige vnwidersprechlige vnd hogste warheit, nit sprech in den helligen ewangelio Mathei 11[,11]: Vnter den sünen der weiber ist kein grosser aufersta[n]den dan Iohannes Baptista, so sprech ich mit lauter stvm vnd in guten glawben vnd vertrawen, daß der hoch geporn leibs halm vnd der auß vnsphrechlich hellig vater sanctus Ioseph, der gesponß der junckfrawen Marie, wer der aller helligst man noch Xpum Ihesum in diser werlt. Wan was alle helligen ie haben gehabt fur vbüng, gnad, verdienst vnd ere vnd wirdikeit vnd hellikeit, die hot der groß hellig vatter Ioseph an im gehabt mit grosser menge vnd crafft vnd volkümmeheit. Kan ich aber mit der warheit daß thun, so wil ich den ser helligen vater Ioseph seczen dem helligen sant Iohans dem dewffer an sein rechten seiten, aber etlich gaden vber in in der hellikeit. ${ }^{85}$

Die Logik, dass die Eltern Jesu den höchsten Rang unter den Heiligen einnehmen müssen, führte jedoch zu der bereits von Bernhard von Clairvaux befürchteten Ausweitung des Kults um die Hl. Familie, ${ }^{86}$ die im Spätmittelalter ihren vorläufigen Höhepunkt erreichte, denn schließlich wurde auch Anna ${ }^{87}$ und Joachim ein Sonderstatus unter den Heiligen eingeräumt. ${ }^{88}$ Jedoch bilden die liturgischen Formulare diese Ehrwürdigkeit der Mitglieder der hl. Sippe nicht $\mathrm{ab}$, da die Verehrungstradition erst lange nach der karolingischen Liturgiereform einsetzte. ${ }^{89}$

85 Joseph, Cod. st 451 (Nr. 9), fol. $157^{\text {ra }}$.

86 Bernhard von Clairvaux: Epist. CLXXIV,6 (PL 182, 334D-335A): Quid adhuc addendum his putamus honoribus? Ut honoretur, inquiunt, et conceptus, qui honorandum praeivit partum, quoniam si ille non praecessisset, nec iste esset qui honoratur. Quid si alius propter eamdem causam, etiam utrique parenti eius festos honores asserat deferendos? Sed et de avis ac proavis idipsum posset pro simili causa quilibet flagitare, et sic tenderetur in infinitum, et festorum non esset numerus.

87 Dörfler-Dierken, S. 63: „So wurde Anna, in einer Situation der allgemeinen Akzeptanz ihrer Verehrung, für die Diskussion um die Empfängnis ihrer Tochter funktionalisiert.“

88 Wie bspw. die zahllosen im Spätmittelalter gegründeten Bruderschaften belegen; siehe Dörfler-Dierken, S. 253-254. Vgl. Boehms Begründung in der Predigt Sermo de S. Anna, Cgm 371 (Nr. 3), fol. $55^{\mathrm{r}-\mathrm{v}}$ : Nun ist eß sag, haben wir lip den sun gottis, Ihesum Cristum, wollen wir eren sein wirdige vnd reine mütter Maria, so sollen wir mit nichten auf horen von dem lob seiner anfrawen, der aller helligsten Anne.

89 Vgl. Odenthal, S. 25: Auch die Bezeichnung ,bonifatianisch-karolingische Liturgiereform“ wird verwendet, um den ,komplexe[n] Verschmelzungsvorgang‘ liturgischer Traditionen zu bezeichnen. Vgl. auch Argarate für die Bedeutung der mittelalterlichen Liturgiereformen als ,transformation culturelle'. 


\section{Die Konsequenz für Boehms Josefstraktat}

Mit dieser Diskrepanz zwischen zugesprochener virtus und Fehlen eines Propriums für den hl. Josef setzt sich Boehm im Folgenden auseinander. Seine Hinweise auf die Festpraxis im Augustiner-Chorherrenstift Rebdorf sind daher von besonderem Aufschlusswert:

Nun zu dem nevnten: Ioseph hot groeß loen, verdienst vnd frewdt mit allen peichtigern in dem himel, wan er ist gewest ein worer gotlicher peichtiger. Was ist ein confessor? Das ist ein peichtiger, dan ein cristen mensch, der do recht in got glewbt vnd helt den glawben aüs libe auch in den wercken. Als man singt von den peichtigern also in dem [h]ymnus: Der peichtiger ist gutig, fursichtig, demutig, geschawmig vnd vernunftig vnd messig vnd kewsch. Auch singt man in der metten in dem vers des achten respons also: Segt ein mensch oen clag, ein warer diener gotis, der sich obczewgt von allen vbel vnd pleibt in seiner vnschuldikeit. Also ist Ioseph gewesen, oen alle zweifel, hie auf erden auß der gnad der peywanung des hern Ihesu, der do ist ein kunig aller tugent vnd auß pey wanung der kunige aller gnaden vol Maria [...]. Wan es spricht Gregorius: Die crafft des almechtigen hot Mariam vmb geben mit seim schaten seiner gnaden. Die hot si auch oen allen zweifel auch mit gedeilt dem helligen Ioseph, wan als stet geschriben in dem 6 puch sant Brigitte: Do Ioseph durch des engels wort ward vnderweist vnd legt von im den arckwan, von meiner entpfangung in dem leib oen sein wissen, do hub er an zu verwilligen pey mir zu pleiben. Dise wort sagt Maria zu Brigitta. ${ }^{90}$

Als Beleg für die besondere Auserwähltheit dient dem Kompilator die Liturgie. Josef wird als Bekenner verehrt, weshalb dann die Aussagen über den Heiligentyp confessor auf den nutritius Christi übertragen werden dürfen. $\mathrm{Zu}$ denken wäre bspw. an den Hymnus Gratulare sponsa Christi ${ }^{11}$ oder auch an das von Boehm erwähnte Responsum Ecce homo sine querela ${ }^{92}$ aus dem CommuneFormular De uno confessore des Breviarium Eystetense..$^{93}$ Ob die Verweise auf die Liturgie nun einen Anstoß liefern sollten oder aber eine Reaktion auf eine bereits geänderte Praxis darstellen, ist auf der Grundlage der vorhandenen Quellen nicht mehr zu entscheiden. Doch fügt sich Boehms Traktat über den hl. Josef in die spätmittelalterliche Tendenz ein, die Feste zu Ehren Mariens, Annas und Josefs aufzuwerten. ${ }^{94}$ Die offensichtlichen amplificationes gegenüber Gersons

90 Joseph, Cod. st 451 (Nr. 9), fol. $177^{\mathrm{va}-\mathrm{vb}}$.

$91 \mathrm{AH}$ 9, S. 54, Nr. 66.

92 Vgl. CAO 6592.

93 Breviarium Eystetense, Bd. 4, fol. 340 .

94 Dieses Interesse ergab sich wohl aus dem Potenzial, das Kleriker für die Laienbelehrung sahen, durch eine Idealisierung des „Lebensstil[s] der Mitglieder der hl. Sippe“ eine „Gott wohlgefällige[n] Lebensweise“ zu fördern. Dörfler-Dierken, S. 253. 
Sermones durch Stammbäume, legendarische Erzählungen und Erläuterungen der Liturgie sind nicht bloße Ausschmückungen, auch wenn deren meditativer Mehrwert bereits hinreichend die Ausweitung rechtfertigen könnte, sondern zielen auch auf eine erweiterte Betrachtung des Phänomens der Verehrung der Hl. Familie ${ }^{95}$ und besonders auch des hl. Josef im zeitgenössischen Kontext:

Also gleich die sun Ihesus vnd der mond Maria vnd die stern des himels, das sein die helligen engel, haben geert dern wirdigen vatter vnd hern Ioseph, wie als ein haws vatter in dem haws vnd wie ein hern, der do ist ein hawpt seiner frawen. Dor vmb wer ist in angsten vnd noten, der ruff an sant Ioseph, wan er vermach groeß vor gottis angesigt. Hot in got geert auf erden, noch mer ert in got itzund in dem himel vnd versagt im nigs. Als ich gelesen hab in dem schwaben landt, in der stat oder closter zu sant Gallen, do singt man alle tag frwe ein meß von vnser liben frawen vnd albe[i] list man auch ein besundere collect in der selbigen meß von sant Ioseph, dem spons Marie, vnd die zw collect beschlewst man mit einem pro dominum vnd die trit collect ist albeg von sant Ioachim vnd von sant Anna, vnd das ist von dem pobst bestetigt zu halten werden in ewig zeit etc. ${ }^{96}$

Ein Officium Beatae Virginis Mariae zur Laudes an jedem Tag der Woche ist in der Tat im Kloster St. Gallen belegt; ${ }^{97}$ auch wird dabei an Anna und Josef gedacht. ${ }^{98}$ Wie Boehm die Kunde von der liturgischen Praxis und den Kollekten ${ }^{99}$ erreichte, bleibt unklar, doch zeigt er sich bestens über aktuelle Entwicklungen informiert, wenn ihm das erst 1475 gestiftete Officium und die seit 1480 eingeführte Kollekte ${ }^{100}$

95 Joseph, Cod. st 451 (Nr. 9), fol. 167 $7^{\mathrm{vb}}-168^{\text {ra }}$ : Joseph der hellig vnd gerecht man mit seiner erbeit vnd mve vnd fleiß hot ernert den sun Iesum Xpum mit seiner mütter Maria. Daß ist ein newe vnd aller helligiste triueltikeit, die vns auf erden ist auferstanden, vns zu eren vnd sellikeit: Ihesus der sun, Maria die mutter, Ioseph geheissen ein vatter. Es spricht Iohannes Gerson in einer predigt von der gepurt Marie also: Ich begert, das ich genunck wort mocht haben vnd erfinden zu aüß legen das hoch vnd groß hellig gotlich werck, das von anbeging der werlt wis vff hewt ist plieben verporgen. Ia, ich mein die zu verwunderlichen vnd wirdigen triveltikeit: Ihesu, Marie vnd Ioseph. Ich het wol den willen, aber das vermügen find ich in mir nigt. Wir mogen gedencken wie auß der naturlicher frevntschafft entspringt ein grosse libe vnd fleiß vnd dinstperlikeit vnd neigüng des svns zu der mütter vnd der mütter zu irem man vnd auch aller peider, das ist des suns, vnd auch der mutter gegen dem aller trewsten vnd aller fleissigsten verweser vnd ernerer vnd havsvatter Ioseph, der do was das hewbt vnd prelat Marie mit magt vnd gewalt, der do als ein ee man mocht ir gepieten, gleich als Maria was gewaltig vber iren sun Ihesum auß dem recht der naturlichen mütterschafft. Vgl. Gerson: Sermo de nativitate (Du Pin III, Sp. 1356B).

96 Joseph, Cod. st 451 (Nr. 9), fol. $184^{\mathrm{va}}$.

97 Vgl. Bruggisser-Lanker, S. 186.

98 Siehe in diesem Tagungsband Lenz: Marienverehrung, S. 11-45.

99 Vgl. Lenz: Reichsabtei, S. 402, Anm. 141.

100 Vgl. in diesem Tagungsband Lenz: Marienverehrung, S. 11-45. 
für den hl. Josef im Detail bekannt sind. ${ }^{101}$ Sogar die Regelung, „dass Weltpriester der umliegenden Kapellen in der Klosterkirche liturgische Dienste [...] verrichteten“, um den Gesang zu unterstützen, ${ }^{102}$ deutet Boehm vielleicht an, wenn er die Formulierung in der stat oder closter zu sant Gallen verwendet. Wie die Ausführungen von Lenz zum Tropus $O$ Maria benedicti sint parentes tui zeigen, ist in dieser Frühmesse, insofern der Tropus „die Lehre der Unbefleckten Empfängnis Mariens [propagiert]“, ${ }^{103}$ wiederum ein Hinweis auf die inhaltliche Verbindung zwischen der Entwicklung der Marienverehrung und der stetig anwachsenden Bedeutung des Josefkults gegeben. ${ }^{104}$ Die ,Eigenständigkeit‘ von Boehms Traktat besteht, trotz der unverkennbaren Abhängigkeit vom Traktat des Petrus de Alliaco sowie von den Predigten Gersons, dann aber vor allem im Praxisbezug, indem er mittels Verweisen auf die Marienliturgie und den Usus im Umgang mit dem Gedenktag des hl. Josef andernorts Konsequenzen für die eigene Kommunität fordert. Ein Hinweis auf das Kloster St. Gallen, das für die Pflege der Liturgie seit Notker Balbulus in der Christenheit bekannt war, und auf das MuttergottesOffizium, welches vom Papst ausdrücklich bestätigt worden sei, ${ }^{105}$ so Boehm (s. o.), darf als starker Appell gelten.

Die Intention des Augustiner-Chorherren, die eigenen liturgischen Traditionen $\mathrm{zu}$ hinterfragen und Impulse $\mathrm{zu}$ Veränderungen $\mathrm{zu}$ geben, ist evident. Das Vorhaben, das Josefsfest in Rebdorf zu etablieren (?), fügt sich in die Bemühungen des Autors Boehm ein, ${ }^{106}$ das in Musterpredigten und Traktaten kodifizierte Wissen der Zeit in einer Phase intensiver Reformtätigkeiten im Konvent, aber auch der Eichstätter Bischöfe, ${ }^{107}$ den liturgischen Vorgaben vor Ort anzupassen und vice versa die Liturgie zu bereichern. Er berücksichtigte daher bei seiner Kompilationsarbeit alles, was ihm durch Liturgica, ,sermon collections` und ,preaching tools‘ ${ }^{108}$ aller Art zugänglich war. Damit führt er praktisch, in seinen Sermones und in dem hier betrachteten Josefstraktat, vor, wie mit dem Anwachsen der liturgischen Möglichkeiten - die sich aus Marienfesten und der ,neuen“

101 Auch eine Stiftung des Kaplans Knüsli in St. Gallen ,zur Beförderung des Josefskultes` fällt in diese Zeit; siehe Barth, S. 19.

102 Lenz: Reichsabtei, S. 398.

103 Lenz: Marienverehrung (in diesem Tagungsband), S. 16.

104 Vgl. Barth, S. 15.

105 Siehe Lenz: Reichsabtei, S. 402, Anm. 142.

$106 \mathrm{Zu}$ den verbreitetsten Sammlungen diesen Typs vgl. Thayer, S. 36-37.

107 Siehe die Beiträge im Tagungsband ,Reform und früher Humanismus‘, hg. von Jürgen Dendorfer, darin besonders den Aufsatz von Bärsch.

108 Einen Überblick über ,preaching tools‘ bieten Kaske, Groos, Twomey. 
Josefsfrömmigkeit ergeben - auch im Hinblick auf die Wissensvermittlung in der Volkssprache produktiv umgegangen werden kann.

\section{Literaturverzeichnis}

Adamus Scotus: Sermones, ser. XXXVIII: In eadem dominica infra octavam nativitatis Domini. De interno cordis nostri statu (PL 198, 342-352).

Ambrosius Mediolanensis: Expositio Evangelii secundum Lucam (PL 15, 1526-1850).

Argarate, Pablo: Les réformes liturgiques carolingienne et grégorienne. In: Questions liturgiques 93 (2012), S. 157-170.

Bärsch, Jürgen: Die Erneuerung des gottesdienstlichen Lebens zur Zeit des Bischofs Johann von Eych. In: Reform und früher Humanismus in Eichstätt. Bischof Johann von Eych (1445-1464). Hg. von Jürgen Dendorfer. Regensburg 2015 (Eichstätter Studien 69), S. 213-231.

Barth, Médard: Die Verehrung des heiligen Josef im Elsass vom Mittelalter bis auf die Gegenwart. Hagenau 1970 (Éditions de la Société d'Histoire de l'Église d'Alsace 67).

Berger, David: Jungfräulicher Bräutigam und Vater Jesu: der hl. Joseph in thomistischer Betrachtung. In: Teresianum 57 (2006), S. 134-147.

Bernardus Claraevallensis: De moribus et officio episcoporum tractatus seu epistola XLII ad Henricum archiepiscopum senonensem (PL 182, 807-834).

Bernard von Luxenburg: Compilatio in recomendationem beati Josephi. Colonia 1510 [BSB München, http://daten.digitale-sammlungen.de/ db/bsb00003133/images/].

Breviarium Eystetense im Auftrag von Wilhelm von Reichenau, Bischof von Eichstätt. 4 Bde.

Bd. 3: Proprium de tempore. Proprium de sanctis. Würzburg 1483 [BSB München, urn:nbn: de:bvb:12-bsb00026406-7].

Bruggisser-Lanker, Therese: Musik und Liturgie im Kloster St. Gallen in Spätmittelalter und Renaissance. Göttingen 2004 (Abhandlungen zur Musikgeschichte 13).

CAO, Bd. 4: Responsoria, versus, hymni et varia. Rom 1970.

Catalogus Sanctorum et gestorum eorum. Ed. Petrus de Natalibus. Lugdunum 1514 [UB Freiburg, urn:nbn:de:bsz:25-digilib-883].

De Dieu, Jean: Sainte Anne et l'immaculée conception. In: Études franciscaines 30 (1934), S. 16-39.

Dendorfer, Jürgen (Hg.): Reform und früher Humanismus in Eichstätt. Bischof Johann von Eych (1445-1464). Regensburg 2015 (Eichstätter Studien 69).

Denzinger, Heinrich: Enchiridion symbolorum definitionum et declarationum de rebus fidei et morum. Kompendium der Glaubensbekenntnisse und kirchlichen Lehrentscheidungen. Lateinisch-Deutsch. Hg. von Peter Hünermann. Freiburg, Basel, Wien ${ }^{43} 2010$.

Dörfler-Dierken, Angelika: Die Verehrung der heiligen Anna in Spätmittelalter und früher Neuzeit. Göttingen 1992 (Forschungen zur Kirchen- und Dogmengeschichte 50).

Falch, Simon: Das Predigtœuvre des Rebdorfer Augustiner-Chorherren Balthasar Boehm (†1530) als vorreformatorische Wissenssumme. Diss. Eichstätt 2015 [im Druck].

Fink-Lang, Monika: Untersuchungen zum Eichstätter Geistesleben im Zeitalter des Humanismus. Regensburg 1985 (Eichstätter Beiträge 14, Abteilung Geschichte). 
Grotefend, Hermann: Zeitrechnung des deutschen Mittelalters und der Neuzeit. 2 Bde, Hannover 1891-1898, hier nach der HTML-Version von Dr. H. Ruth (2004) [http://bilder.manuscripta-mediaevalia.de/gaeste//grotefend/grotefend.htm].

Guillermus Parisiensis: Postilla Guillermi super Epistolas et Euangelia de tempore et de sanctis et pro defunctis. Basel (um 1501) [BSB München, urn:nbn:de:bvb:12-bsb00007966-7].

Hasebrink, Burkhard, Hans-Jochen Schiewer: Art. ,Predigt'. In: RLW 3 (2003), S. 151-156. Heal, Bridget: The Cult of the Virgin Mary in Early Modern Germany. Protestant and Catholic Piety, 1500-1648. Cambridge 2007.

Heinzer, Felix: Karwoche in Blaubeuren. Zur liturgischen Nutzung von Chor und Klosterkirche. In: Das Kloster Blaubeuren. Der Chor und sein Hochaltar. Hg. von Anna Moraht-Fromm, Wolfgang Schürle. Stuttgart 2002, S. 33-39.

Herolt, Johannes: Sermones de tempore. Darin: Sermones de sanctis; Promptuarium exemplorum secundum ordinem alphabeti; Promptuarium de miraculis beatae Mariae virginis. Nürnberg 1496 [BSB München, urn:nbn:de:bvb:12-bsb00043084-3].

Hilg, Hardo: Die mittelalterlichen Handschriften der Universitätsbibliothek Eichstätt. Bd. 1: Aus Cod. st 1-Cod. st 275. Wiesbaden 1994 (Kataloge der Universitätsbibliothek Eichstätt 1,1).

Höcherl, Josef: Kloster Rebdorf. Von der Gründung bis zur Gegenwart. Rebdorf 1996.

Horst, Ulrich OP: Dogma und Theologie. Dominikanertheologen in den Kontroversen um die Immaculata Conceptio. Berlin 2009 (Quellen und Forschungen zur Geschichte des Dominikanerordens, N. F. 16).

Johannes Chrysostomus: Kommentar zum Evangelium des hl. Matthäus. Aus dem Griechischen übers. von Joh. Chrysostomus Baur. Kempten, München 1915 (Des heiligen Kirchenlehrers Johannes Chrysostomus ausgewählte Schriften Bd. 1, Bibliothek der Kirchenväter, 1/23).

Johannes Gerson: Epistula ad quedam ut celebretur Festum sancti Joseph, alia epistola. In: ders.: Opera Omnia, Bd. 4. Hg. von Louis Ellies Du Pin. Antwerpen 1706 [Nachdruck Hildesheim, Zürich, New York 1987], Sp. 732-736.

Johannes Gerson: Sermo de nativitate. In: ders.: Opera Omnia, Bd. 3. Hg. von Louis Ellies Du Pin. Antwerpen 1706 [Nachdruck Hildesheim, Zürich, New York 1987], Sp. 1345-1360.

Kaske, Robert Earl, Arthur Groos, Michael W. Twomey: Medieval Christian Literary Imagery. A Guide to Interpretation. Toronto, Buffalo, London 1988 (Toronto Medieval Bibliographies 11).

Keller, Karl Heinz: Die mittelalterlichen Handschriften der Universitätsbibliothek Eichstätt, Bd. 2: Aus Cod. st 276-Cod. st 470. Wiesbaden 1999 (Kataloge der Universitätsbibliothek Eichstätt 1,2).

Kleinschmidt, Beda: Die heilige Anna: ihre Verehrung in Geschichte, Kunst und Volkstum. Düsseldorf 1930 (Forschung für Volkskunde 1-3).

Lamarzelle, Agnès de: Joseph, le père du fils de la Promesse. Étude de MT 1,18-25: L'annonciation à Joseph. In: Nouvelle Revue Théologique 135 (2013), S. 529-548.

Lentes, Thomas: A maioribus tradita. Zur Kommunikation von Mythos und Ritus im mittelalterlichen Messkommentar. In: Literarische und religiöse Kommunikation in Mittelalter und Früher Neuzeit. Hg. von Peter Strohschneider. Berlin 2009, S. 324-370.

Lenz, Philipp: Reichsabtei und Klosterreform. Das Kloster St. Gallen unter dem Pfleger und Abt Ulrich Rösch 1457-1491. St. Gallen 2014 (Monasterium Sancti Galli 6).

Littger, Klaus Walter: Die Bibliothek des Augustiner-Chorherrenstifts Rebdorf. In: Kloster und Bibliothek: zur Geschichte des Bibliothekswesens der Augustiner-Chorherren in der Frühen Neuzeit. Tagung der Akademie der Augustiner-Chorherren von Windesheim vom 12. bis zum 14. November 1998 in der Benediktinerabtei Mariendonk bei Kempen. Hg. von 
Rainer A. Müller. Paring 2000 (Congregatio Vindesemensis-Victorina, Publikationen der Akademie der Augustiner-Chorherren von Windesheim 2), S. 109-138.

Littger, Klaus Walter: Eichstätt, Universitätsbibliothek. In: Handbuch der historischen Buchbestände in Deutschland. Bd. 11. Hg. von Eberhard Dünninger. Hildesheim, Zürich, New York 1997, S. 216-239.

Lohse, Bernhard: Epochen der Dogmen-Geschichte. ,Dogmen verschweigen heißt Dogmen verleugnen.' 9. Aufl. Berlin 2011 (Red Guide 5).

Maas-Ewerd, Theodor: Art. ,Marienfeste'. In: LexThK³ 3 (1997), Sp. 1370-1374.

Marbach, Carl: Carmina Scripturarum. Scilicet antiphonas et responsoria ex sacro scripturae fonte in libros liturgicos sanctae ecclesiae romanae derivata collegit et edidit Carolus Marbach. Straßburg 1907, 2. Nachdruck. Hildesheim, Zürich, New York 1994.

Missale Eystetense mit dem Mandat von Wilhelm von Reichenau, Bischof von Eichstätt. Kanonholzschnitt von Michael Wolgemut. Eichstätt 1494 [BSB München, urn:nbn:de:bvb: 12-bsb00032906-4].

Oddo Astensis: Expositio in Psalmos (PL 165, 1152-1297).

Odenthal, Andreas: Liturgie vom Frühen Mittelalter zum Zeitalter der Konfessionalisierung. Tübingen 2011 (Spätmittelalter, Humanismus, Reformation 61).

Petrus Damiani: De caelibatu sacerdotum (PL 145, 380-388).

Petrus de Alliaco: Tractatus de duodeci honoribus sancti Joseph (1497-1498) [Bibliothèque nationale de France, http://gallica.bnf.fr/ark:/12148/bpt6k110642d].

Preuss, Eduard: Die römische Lehre von der unbefleckten Empfängniss [!]. Aus den Quellen dargestellt und aus Gottes Wort widerlegt. Berlin 1865.

Roth, Dorothea: Die mittelalterliche Predigttheorie und das Manuale Curatorum des Johann Ulrich Surgant. Basel 1956.

Ruf, Paul (Bearb.): Bistum Eichstätt. München 1969 (Mittelalterliche Bibliothekskataloge Deutschlands und der Schweiz 3,2).

Schiewer, Regina D.: Die deutsche Predigt um 1200. Ein Handbuch. Berlin, New York 2008.

Schneider, Karin: Art. ,Silvester von Rebdorf‘. In: VL² 8 (1992), Sp. 1248-1253.

Schneyer, Johannes Baptist: Repertorium der lateinischen Sermones des Mittelalters für die Zeit von 1350-1500. CD-ROM-Edition. Hg. von Ludwig Hödl, Wendelin Knoch. Münster 2001.

Schnurrer, Ludwig: Rothenburg als Wallfahrtsstadt im Spätmittelalter. In: Die oberdeutschen Reichsstädte und ihre Heiligenkulte. Traditionen und Ausprägungen zwischen Stadt, Ritterorden und Reich. Hg. von Klaus Herbers. Tübingen 2005 (Jakobus Studien), S. 69-100.

Schumacher, Joseph: Die Bedeutung der Verehrung des heiligen Joseph im Kontext der Heiligenverehrung der Kirche [http://www.theologie-heute.de/Verehrung_des_HL_ Joseph2.pdf (26. Juli 2016)].

Seitz, Joseph: Die Verehrung des hl. Joseph in ihrer geschichtlichen Entwicklung bis zum Konzil von Trient. Freiburg i. Br. 1908.

Signori, Gabriela: Die verlorene Ehre des heiligen Joseph oder Männlichkeit im Spannungsfeld spätmittelalterlicher Altersstereotypen. Zur Genese von Urs Grafs ,Heiliger Familie‘ (1521). In: Verletzte Ehre. Ehrkonflikte in Gesellschaften des Mittelalters und der Frühen Neuzeit. Hg. von Klaus Schreiner, Gerd Schwerhoff. Köln, Weimar, Wien 1995 (Norm und Struktur. Studien zum sozialen Wandel in Mittelalter und Früher Neuzeit 5), S. 183-213.

Thayer, Anne: Penitence, Preaching and the Coming of the Reformation. Aldershot 2002 (St Andrews Studies in Reformation History). 
Thomas de Aquino: Catena aurea in quatuor Evangelia. http://www.corpusthomisticum.org/ (1. Juni 2016).

Thomas de Aquino: Summa Theologiae. http://www.corpusthomisticum.org/ (1. Juni 2016). Weidenhiller, Egino: Art. ,Meister Bernart'. In: VL² 1 (1978), Sp. 744.

Wenzel, Siegfried: Medieval Artes Praedicandi: A Synthesis of Scholastic Sermon Structure. Toronto 2015.

Wucherpfennig, Ansgar: Josef der Gerechte. Eine exegetische Untersuchung zu Matthäus 1-2. Freiburg i. Br. u. a. 2008 (Herders Biblische Studien 55).

Zschoch, Hellmut: Die Christenheit im Hoch- und Spätmittelalter. Göttingen 2004 (UTB 2520). 